\title{
Outcomes of home health care and telephone home visit by pharmacist in type 2 diabetes patients on hospital readmission: a case study at Bangplama Hospital, Suphanburi Province, Thailand
}

\author{
Nilawan Upakdee ${ }^{1 *}$, Suwicha Mankongdee ${ }^{2}$ \\ From 6th Postgraduate Forum on Health Systems and Policies \\ Melaka, Malaysia. 21-22 May 2012
}

\section{Background}

The objective of this study was to compare outcomes of home health care and telephone home visit by pharmacist in type 2 diabetes patients on hospital readmission at Bangplama hospital, Suphanburi Province.

\section{Materials and methods}

Inclusion criteria was admitted patients with first diagnosed conditions with low or high blood sugar level. This study was done during December 2010 to February 2011. This study was true experimental design with randomized block that is similar in co-morbidites and age range. Fourteen patients were classified into two groups, each group composed of 7 cases. Control group received home health care and study group received telephone home visit. Primary outcome was readmission within 28 days. Economic outcome was charge of care savings from preventing hospital readmission.

\section{Results}

The results showed that control group had none of patient readmission, while $14.3 \%$ of study group was readmitted. Clinical outcomes were mean fasting blood sugar (FBS) and blood pressure (BP) first time at discharge and second time within 28 days. In control group, average mean FBS were $175.29 \mathrm{mg} / \mathrm{dl}$ and $154.29 \mathrm{mg} / \mathrm{dl}$, respectively. In the study group, average mean FBS were $120.57 \mathrm{mg} / \mathrm{dl}$ and $120.85 \mathrm{mg} / \mathrm{dl}$, respectively. Systolic blood pressure in the control group was decreased at $129.14 \mathrm{mmHg}$ and $117.85 \mathrm{mmHg}$, respectively. While in the study group were almost equal to $137.00 \mathrm{mmHg}$ and $135.85 \mathrm{mmHg}$, respectively. Diastolic blood pressure in the control group was increased at $79.57 \mathrm{mmHg}$ and $82.145 \mathrm{mmHg}$, respectively. In the study group were increased at $76.85 \mathrm{mmHg}$ and $81.28 \mathrm{mmHg}$, respectively. Direct medical care charge from prevent hospital readmission in control and study group were 49,905 Baht and 40,108 Baht, respectively.

\section{Conclusions}

The results of this study show that both home health care and telephone home visit by pharmacist in diabetes patients were beneficial for preventing readmission.

\section{Author details}

${ }^{1}$ Faculty of Pharmaceutical Sciences, Naresuan University, Phitsanulok,

Thailand. ${ }^{2}$ Pharmacy Department, Bangplama Hospital, Suphanburi, Thailand.

Published: 27 November 2012

doi:10.1186/1471-2458-12-S2-A20

Cite this article as: Upakdee and Mankongdee: Outcomes of home health care and telephone home visit by pharmacist in type 2 diabetes patients on hospital readmission: a case study at Bangplama Hospital, Suphanburi Province, Thailand. BMC Public Health 2012 12(Suppl 2):A20.

${ }^{1}$ Faculty of Pharmaceutical Sciences, Naresuan University, Phitsanulok,

Thailand

Full list of author information is available at the end of the article 